\title{
SISTEM INFORMASI GEOGRAFIS PEMETAAN SEKOLAH MENENGAH KEJURUAN DI KABUPATEN LABUHANBATU MENGGUNAKAN WEBGIS
}

\author{
Lisma Zahara ${ }^{1}$, Ibnu Rasyid Munthe ${ }^{2 *}$, Ali Akbar Ritonga ${ }^{3}$ \\ ${ }^{1,2}$ Manajemen Informatika, Universitas Labuhanbatu \\ ${ }^{3}$ Teknologi Informasi, Fakultas Sains dan Teknologi, Universitas Labuhanbatu \\ email: *ibnurasyidmunthe@gmail.com
}

\begin{abstract}
Labuhanbatu Regency is a district that has many Vocational High Schools (SMK) which are very attractive to the community. Because each Vocational High School has its own vocational fields, for example Health, Automotive, Offices, and others. The existence of this Geographic Information System makes it easy for users to find Vocational High School routes. Vocational High Schools are schools that make students or prospective students even more skilled. In making this Geographic Information System requires Systems Development Life Cycle to analyze gradually, and Webgis to display maps as well as GPS to ascertain the location of the earth's surface and use UML design such as activity diagrams, sequence diagrams, and usecase. There is also a waterfall method in making this Geographic Information System such as its analysis, implementation, design, maintenance and also the testing phase. The Testing Phase uses the BlackBox to test the system whether it is running well or not and is suitable for use by users.
\end{abstract}

Keywords: BlackBox Testing; Geographic Information System; Google Maps; GPS; UML; Vocational High School

\begin{abstract}
Abstrak: Kabupaten Labuhanbatu termasuk kabupaten yang memiliki banyak Sekolah Menengah Kejuruan (SMK) yang sangat diminati masyarakat. Karena setiap SMK memiliki kejuruan masing-masing dalam bidangnya misalkan Kesehatan, Otomotif, Perkantoran, dan lain-lain. Adanya Sistem Informasi Geografi ini memudahkan para pengguna untuk mencari rute Sekolah Menengah Kejuruan. Sekolah Menengah Kejuruan adalah sekolah yang menjadikan para siswa atau calon siswa lebih trampil lagi. Dalam pembuatan Sistem Informasi Geografi ini memerlukan Systems Development Life Cycle menganalisis secara bertahap, dan Webgis untuk menampilkan peta juga GPS untuk memastikan letak permukaan bumi dan menggunakan Perancangan UML seperti activity diagram, sequence diagram, dan usecase. Terdapat juga Metode waterfall dalam membuat Sistem Informasi Geografi ini seperti analisanya, implementasi, desain, pemeliharaan dan juga tahap pengujian. Tahap Pengujian menggunakan BlackBox untuk menguji Sistem apakah berjalan baik atau tidak dan sudah layak digunakan bagi pengguna.
\end{abstract}

Kata kunci: Sekolah Menengah Kejuruan; GPS; Peta Google; Sistem Informasi Geografi; Uji BlackBox; UML 
DOI: https://doi.org/10.33330/jurteksi.v7i2.1079

Available online at http://jurnal.stmikroyal.ac.id/index.php/jurteksi

\section{PENDAHULUAN}

Kabupaten Labuhanbatu termasuk kabupaten yang memiliki banyak Sekolah Menengah Kejuruan (SMK) yang sangat diminati masyarakat. Setiap SMK memiliki kejuruan masing-masing atau bisa dikatakan sangat tersebar luas misalkan kejuruan Kesehatan, Otomotif, TKJ, dll. Saat ini peminat masyarakat untuk masuk SMK cukup tinggi karena ketika mereka menyelesaikan pendidikan akan dibekali ketrampilan pada kejuruan mereka masing-masing, biasanya SMK lebih terjun kelapangan langsung walaupun mereka juga mempelajari teori tetapi akan lebih banyak ke Praktek Kerja dan ketika mereka ditengah atau dibangku kelas 2 pendidikan akan ada yang namanya Praktek Kerja Lapangan (PKL) yang akan melatih mereka lebih trampil. Fasilitas pendidikan SMK di Kabupaten Labuhanbatu ini sangat memadai setiap sekolah mampu menyediakan kebutuhan praktek. Maka dari pada itu peminat untuk masuk ke Sekolah SMK ini meningkat sangat pesat.[1]

Sistem Informasi Geografi Sekolah Menengah Kejuruan (SMK) ini sangat penting, karena sebelum mereka memasuki atau mendaftar kesekolah tersebut harus tau informasi sekolah yang akan didaftar atau dijalanin untuk tiga tahun kedepannya. Terutama informasi mengenai Alamat, Akreditasi Sekolah, Status Sekolah Negeri ataupun Swasta nantinya, dan Kejuruan yang tersedia disekolah itu atau bahkan mereka juga ingin tau Kepala Sekolah yang sedang berlaku saat mereka mendaftarkan diri.

Untuk saat ini masyarakat masih kesulitan dalam pencarian informasi termasuk alamat sekolah karena terkadang setiap masyarakat atau calon siswa ingin lebih dekat dari jarak rumah mereka masing-masing. [2]
Maka dari itu dirancang sebuah sistem untuk mengetahui lokasi atau alamat dan informasi sekolah dengan sedetaildetailnya. Yaitu dengan sistem Geographic Information System (GIS) atau disebut dengan webgis, webgis ini dapat menampilkan peta yang ingin kita tuju, juga menampilkan informasi yang disediakan dan menampilkan peta rute perjalanan. Sistem Informasi Geografi ini menggunakan sebuah smartphone dengan jaringan internet yang kuat agar pemetaan nya terlihat jelas. Agar sistem informasi geografi ini berjalan dengan baik diperlukan suatu Systems Development Life Cycle dengan perancangan UML menggunakan metode waterfall.[3] Systems Development Life Cycle ini sebuah analisis sistem yang dilakukan seorang programmer untuk membangun sebuah sistem informasi geografi ini diikuti dengan Perancangan UML yang terdiri dari Activity Diagram, Sequence Diagram, dan UseCase.[4]

Kabupaten Labuhanbatu memiliki dua puluh Sekolah Menengah Kejuruan swasta amaupun negeri dengan berbagai jurusan masing-masing. [6]

Systems Development Life Cycle adalah berupa strategi yang memiliki tahapan-tahapan untuk melakukan sebuah analisa dan membangun suatu rancangan sistem.[7] Systems Development Life Cycle juga termasuk sebagai alat dalam memanajemen sebuah proyek berguna untuk merencanakan pengembangan system, Systems Development Life Cycle ini termasuk metode klasik dalam mengembangkan suatu system.[4] Dalam pembuatan Sistem Informasi Geografi ini menggunakan metode waterfall yang terbagi menjadi 5 tahap yaitu : Analysis, Design, Implementation, BlackBox Testing, dan Maintenance [5].

Sistem Informasi Geografis berfungsi untuk menghasilkan data 
berbentuk geografis, menyimpan data, memasukkan dan memanggil data kembali. SIG merupakan suatu alat bantu berupa informasi yang berbentuk pemetaan.[8]

WebGis adalah tampilan web yang menampilkan pemetaan dengan menggunakan internet. WebGis juga sangat bermanfaat bagi pengguna karena mempermudah pengguna untuk melihat pemetaan yang ingin dituju misalkan Sekolah Menengah Kejuruan (SMK). [9]

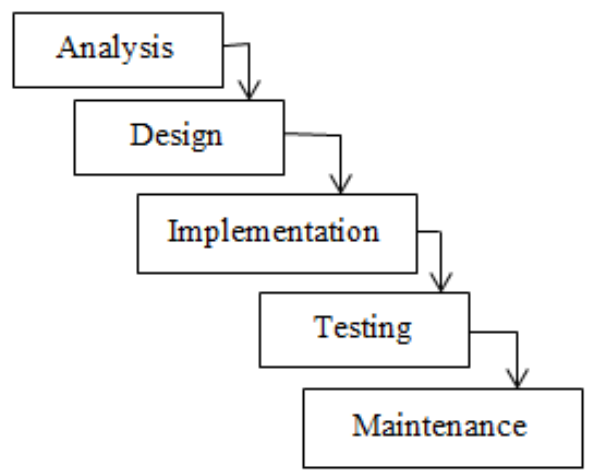

Gambar 1. Model Waterfall

Global Positioning System(GPS) berfungsi sebagai informasi keberadaan suatu tempat dengan bantuan satelit yang beroperasi mengeliling bumi yang mengirimkan sinyal ke alat yang diakses oleh yang membutuhkan info letak lokasi [3]. Google Maps memberikan pelayanan berupa menampilkan suatu peta dunia dan wilayah yang kita inginkan.[10]

\section{METODE}

Metode Waterfall ini tersedia suatu pendekatan yang terurut dapat dimulai dari analisis, desain, implementasi, blackbox, maintenance.[11]

\section{Analysis}

Tahap analysis ini adalah tahap pengum- pulan data dengan cara mensurvei sekolah yang termasuk di Kota RantauPrapat. Agar dapat informasi lebih lengkap atau lebih detailnya yang informasinya akan didokumentasikan.

\section{Design}

\section{UseCase Diagram}

Bagian UseCase ini terdapat dua aktor yang terdiri dari Admin dan User. Dalam Sistem ini Admin dapat mengakses Login, Halaman Admin, Inputkan data Sekolah, juga menentukan Longitude dan Latitude, Admin juga dapat mengedit atau menghapus. Sedangkan User hanya dapat mengkases Halaman Utama Pemetaan, Memilih titik kordinat sekolah yang ingin dituju maka akan muncul Rute Perjalanan.

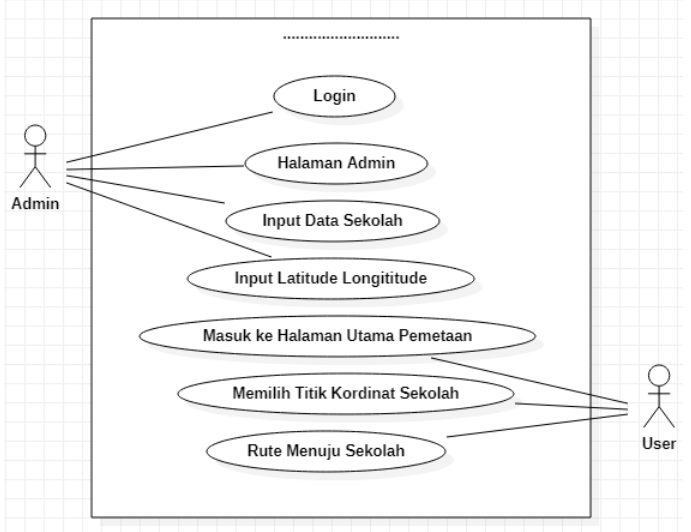

Gambar 2. UseCase Diagram Sekolah

\section{Sequence Diagram}

Pada bagian Sequence admin ini dapat menampilkan menu login dengan menggunakan username 'lismazahara' dan menggunakan password 'lisma12345'. Jika username atau password salah dalam meloginkan maka akan kembali ke menu login lagi, dan jika username atau password benar maka akan masuk ke Halaman Admin. 
DOI: https://doi.org/10.33330/jurteksi.v7i2.1079

Available online at http://jurnal.stmikroyal.ac.id/index.php/jurteksi

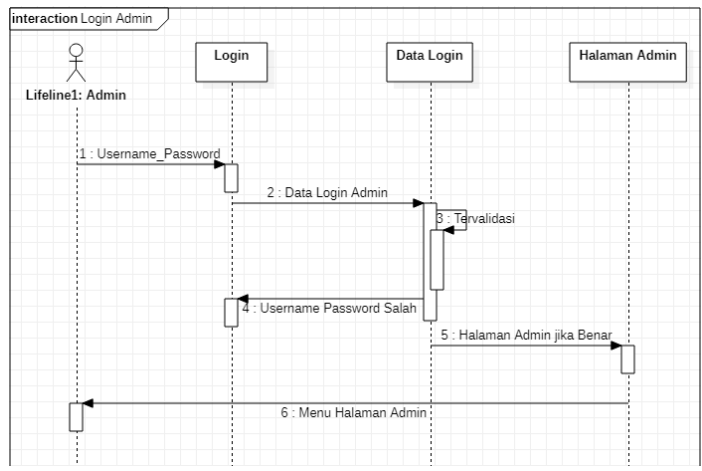

Gambar 3. Sequence Diagram Login Admin

Pada Sequence form input admin dapat menambahkan sekolah yang diinginkan dengan menginputkan Nama Sekolah, Alamat Sekolah, Status Sekolah, Kepala Sekolah, dan juga menginputkan Longitude Latitudenya.

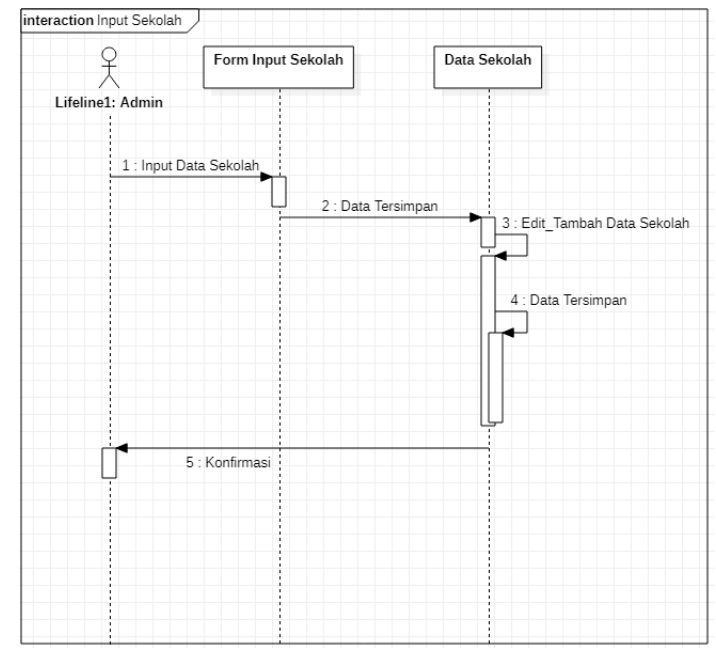

Gambar 4. Sequence Diagram Admin Input Sekolah

Pada Sequence User, Misalkan User memilih tujuan ke SMK N 1 Rantau Utara maka akan ditampilkan peta atau rute perjalanan ke Sekolah yang akan dituju yang berada di Jl. Jend. Ahmad Yani No.32, Kartini, Rantau Selatan, Kabupaten Labuhan Batu.

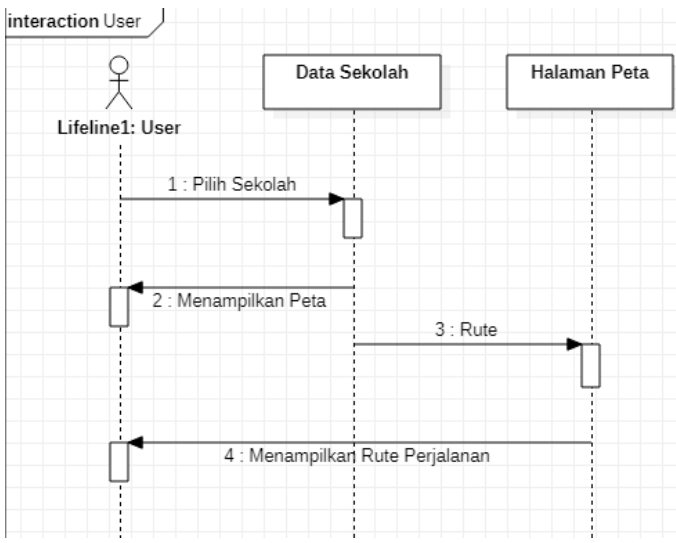

Gambar 5. Sequence Diagram User

\section{Activity Diagram}

Bila admin meloginkan username serta password dengan benar maka akan ke Halaman Admin. Bila username dan password salah, maka akan kembali ke menu login atau menu username dan password.

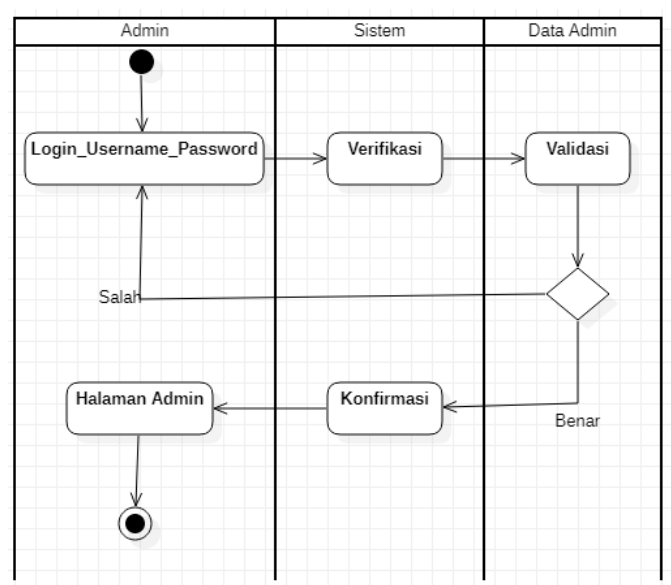

Gambar 6. Activity Diagram Login Ad$\min$

Activity Diagram Login Admin ini dengan menginputkan longitude dan latitude. Misalkan Admin memilih Sekolah SMK N 1 Rantau Utara maka admin dapat mengedit atau menghapus nyaJika data sekolah diinput dengan benar maka data akan tersimpan di Data Sekolah jika data salah dalam penginputan maka akan kembali ke Sistem List Sekolah. 


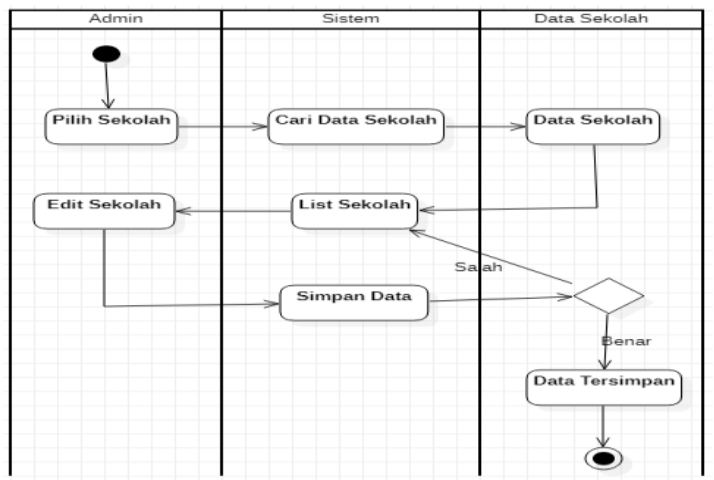

Gambar 7. Activity Diagram Input Sekolah

Activity Diagram pada User, jika User memilih titik SMA N 1 Rantau Utara sebagai tujuannya maka akan tampil peta rute perjalanan ke tujuan tersebut beserta informasi sekolah tersebut dengan titik kordinat yang tepat.

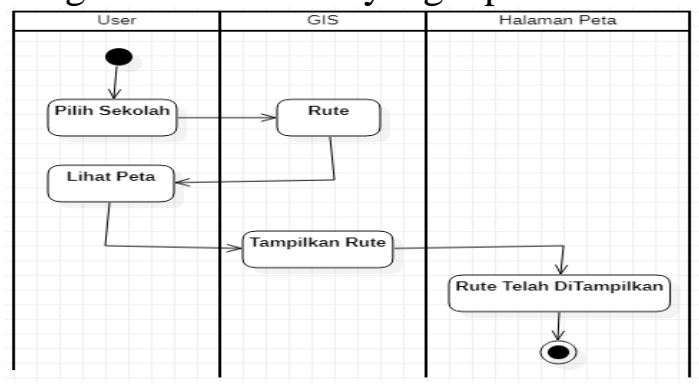

Gambar 8. Activity Diagram User

\section{Implementation}

Dalam implementation ada kebutuhan komputer dengan standartnya. Da- lam pembuatan coding yang dijalankan menggunakan notepad++, dan dalam pembuatan sistem informasi sekolah ini menggunakan sistem pendukung yaitu WEBGIS, GPS, XAMPP, Systems Development Life Cycle, GOOGLE MAPS.[9]

\section{BlackBox Testing}

Pada tahap pengujian ini menggunakan BlackBox apakah sistem layak digunakan atau tidak. Pengujian di tahap ini dimulai dari login, input data sekolah, lalu menentukan titik kordinat maka akan muncul peta atau rute nya.[12]

\section{Maintenance}

Pada tahap pemeliharaan untuk menjaga sistem agar digunakan dengan sebaik mungkin maka perlunya pengembangan sistem tersebut agar terus berjalan dengan baik.[12]

\section{HASIL DAN PEMBAHASAN}

Berdasarkan survei yang dilakukan terdapat 20 Sekolah Menengah Kejuruan (SMK) di Kabupaten Labuhanbatu:

Tabel 1. Daftar Sekolah Menengah Kejuruan

\begin{tabular}{llll}
\hline No. & Nama Sekolah & Status Sekolah & Alamat \\
\hline 1. & SMK Siti Banun Rantau Prapat & Swasta & Ujung Bandar \\
\hline 2. & SMK S Muhammadiyah Rantau Prapat & Swasta & Ahmad Dahlan \\
\hline 3. & SMK S Budi Rantau Prapat & Swasta & Sirandorung \\
\hline 4. & SMK Teladan Rantau Prapat & Swasta & Arrahma \\
\hline 5. & SMK S Kesehatan Sartika & Swasta & Jl. Baru \\
\hline 6. & SMK S Pemda & Swasta & K.H Dewantara \\
\hline 7. & SMK N 3 Rantau Utara & Negeri & W.R Supratman \\
\hline 8. & SMK N 2 Rantau Utara & Negeri & W.R Supratman \\
\hline 9. & SMK N 1 Rantau Utara & Negeri & Jend. Ahmad Yani \\
\hline 10. & SMK S Dewi Sartika Bilah & Swasta & Jl. Negeri Lama \\
\hline 11. & SMK S Al-Bukhary & Swasta & Jl. Komplek Perum \\
\hline 12. & SMK S Al-Azzam Sei Rakyat & Swasta & Dsn V Sei Rakyat \\
\hline 13. & SMK S Mandiri Panai Hulu & Swasta & Jln. Cinta Makmur \\
\hline & & &
\end{tabular}




\section{Halaman Website}

Pada tampilan halaman utama Terdapat menu Home, List Sekolah yang berisi data Sekolah, dan About yang berisi informasi tentang pemilik web. Dan terdapat menu Login disebelah kanan atas.

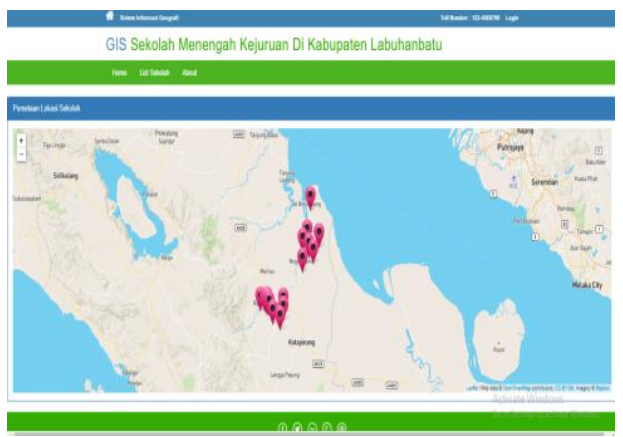

Gambar 9. Halaman Utama Website

\section{Menu Login Admin}

Pada tampilan ini admin harus menginputkan username dengan 'lismazahara' dan password 'lisma12345'

GIS Sekolah : Login

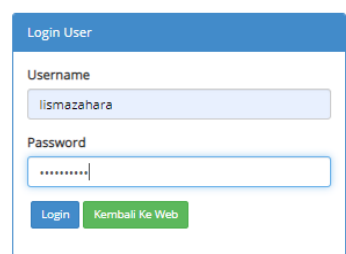

Gambar 10. Menu Login Admin

\section{Menu Pemetaan Sekolah}

Pada menu ini terdapat titik kordinat Sekolah Menengah Kejuruan (SMK) yang sudah diinputkan.

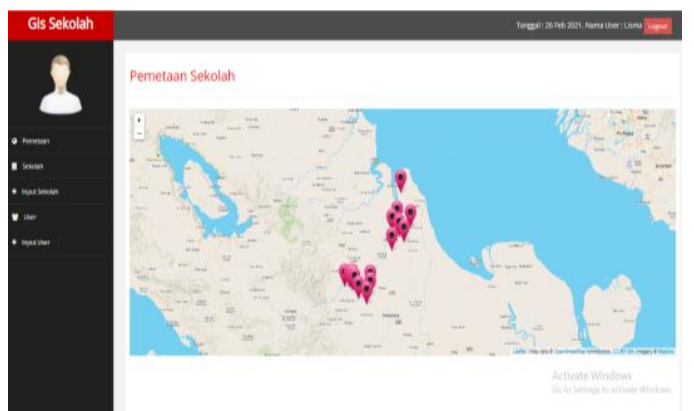

Gambar 11. Pemetaan Sekolah

\section{Tampilan Menu Data Sekolah}

Pada Menu ini terdapat tampilan informasi tentang Sekolah Menengah Kejuruan (SMK) termasuk alamat, status sekolah, gambar sekola, dan Kepala Sekolah.

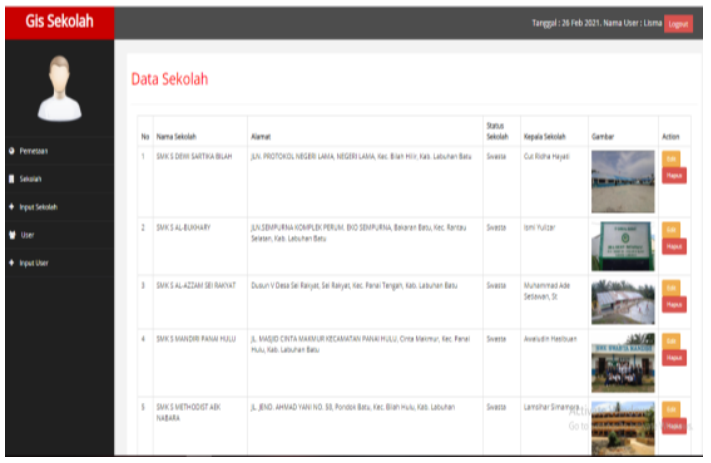

Gambar 12. Menu Data Sekolah

\section{Halaman Detail}

Pada halaman ini menampilkan detail informasi Sekolah tersebut

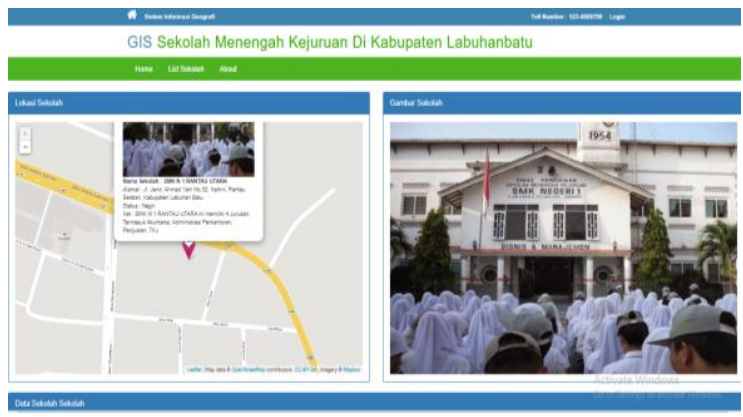

Gambar 13. Halaman Detail

\section{Halaman Rute Perjalanan}

Pada halaman ini dapat menampilkan rutenya misalkan Aek Paing ke SMK N 1 Rantau Utara.

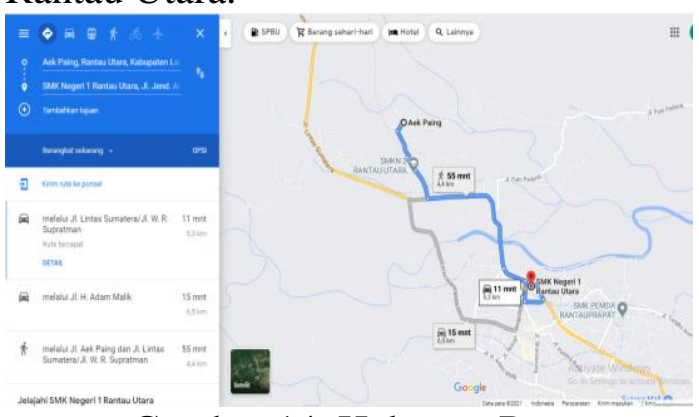

Gambar 14. Halaman Rute 


\section{Pengujian Sistem}

Pada pengujian Sistem Informasi Geografis Sekolah ini menggunakan sebuah Blackbox Testing. Tujuan nya agar dipastikan sistem berjalan dengan baik atau tidak. Ketika diuji dalam Sistem Informasi Geografis Sekolah ini ternyata berjalan dengan baik atau bisa dikatakan berhasil untuk diuji sehingga dapat digunakan oleh pengguna. [12]

Tabel 3. Pengujian sistem

\begin{tabular}{|c|c|c|c|}
\hline Pegujian & $\begin{array}{l}\text { Rincian } \\
\text { Pengujian }\end{array}$ & $\begin{array}{l}\text { Jenis } \\
\text { Pengujian }\end{array}$ & $\begin{array}{l}\text { Hasil } \\
\text { Pen- } \\
\text { gujian }\end{array}$ \\
\hline $\begin{array}{l}\text { Login } \\
\text { Admin }\end{array}$ & $\begin{array}{l}\text { Verifikasi } \\
\text { Data Login }\end{array}$ & $\begin{array}{l}\text { Black Box } \\
\text { Testing }\end{array}$ & Berhasil \\
\hline $\begin{array}{l}\text { Kelola } \\
\text { Data } \\
\text { Sekolah }\end{array}$ & $\begin{array}{l}\text { Tambah } \\
\text { data, Simpan } \\
\text { data, Edit } \\
\text { data, Hapus } \\
\text { data }\end{array}$ & $\begin{array}{l}\text { Black Box } \\
\text { Testing }\end{array}$ & Berhasil \\
\hline $\begin{array}{l}\text { Mempros } \\
\text { es Data } \\
\text { Penggun } \\
\text { a }\end{array}$ & $\begin{array}{l}\text { Tambah } \\
\text { data, Simpan } \\
\text { data, Edit } \\
\text { data, Hapus } \\
\text { data }\end{array}$ & $\begin{array}{l}\text { Black Box } \\
\text { Testing }\end{array}$ & Berhasil \\
\hline
\end{tabular}

\section{SIMPULAN}

Sistem Informasi Geografis (SIG) merupakan sistem yang cukup menarik karena memudahkan para pengguna untuk mengakses rute yang mereka inginkan. Sistem Informasi Geografi ini juga menampilkan fitur-fitur yang banyak tersedia misalkan alamat lengkap dan juga informasi detailnya. Sehingga banyak masyarakat mengetahui terdapat cukup banyak Sekolah Menengah Kejuruan di kabupaten Labuhanbatu ini yang banyak mereka tidak ketahui sehingga mencari sekolah diluar Labuhanbatu. Sistem Informasi Geografis (SIG) ini dirancang dengan menggunakan GPS, Xampp, Sdlc, dan Google Maps. Sistem Informasi ini dirancang juga menggunakan metode waterfall secara bertahap perancangannya melalui perancangan UML.

\section{DAFTAR PUSTAKA}

[1] A. R. Ramadhan, M. Silvana, and H. Suryamen, "Pembangunan Sistem Informasi Geografis Sekolah Menengah Kejuruan Di Kota Padang Berbasis Web Menggunakan Google Maps Api," J. Tek. Inform. dan Sist. Inf., no. November, pp. 1-7, 2016.

[2] M. F. Ghozali, "Pemanfaatan Sistem Informasi Geografis Untuk Pemetaan Sekolah Sma/SMK Di Kota Malang Berbasis Web," vol. 4, no. 2, pp. 230-238, 2020.

A. Hidayat, B. Sudarsono, and B. Sasmito, "Desain Pengembangan Aplikasi Sebaran Pendidikan Berbasis WebGis di Kecamatan Demak Kabupaten Demak," $J$. Geod. Undip, vol. 3, no. 1, p. 85091, 2014.

[4] D. Y. Prasetyo, "Implementasi Geographic Information System (Gis) Penentuan Tampat Ibadah Masjid Di Kecamatan Kempas Kabupaten Indragiri Hilir Provinsi Riau," Sistemasi, vol. 8, no. 1, p. 10, 2019.

[5] M. Mailasari and E. D. Sikumbang, "Metode Waterfall Dalam Implementasi Aplikasi Perpustakaan Berbasis Dekstop," Sistemasi, vol. 8, no. 3, p. 341, 2019.

[6] A. Riansyah, D. Kurniadi, I. Widihastuti, and V. Alfiansyah, "Sistem Informasi Geografis Untuk Pemetan Lokasi Dan Bidang Kompetensi Sekolah 
Menengah Kejuruan ( SMK ) Di Kota Tegal," J. Elektro dan Inform. Unissula, vol. 3, no. 1, pp. 45-51, 2018.

[7] I. R. Munthe, "Perancangan Sistem Informasi Pengarsipan Data Penduduk Pada Kantor Camat Bilah Hulu Kabupaten Labuhan Batu Dengan Metode System Develovment Life Cycle (Sdlc)," J. Inform., vol. 5, no. 1, pp. 22-31, 2019.

[8] V. F. Anjani and N. Zahrati, "Pemetaan Sebaran Mahasiswa Politeknik Negeri Batam Berdasarkan Asal Sekolah Menggunakan WebGIS," J. Integr. Vol. 7, No. 1, vol. 7, no. 1, pp. 7176, 2015.

[9] M. I. Anshory, F. Renaldi, and H. Ashaury, "Sistem Informsi Geografis Sebaran Pendidikan
Pada Tingkat Sekolah Dasar Dan Menengah Pertama Di Wilayah Kabupaten Bandung Barat Berbasis Web," pp. 81-86, 2019.

[10] S. Informasi, "PENDAHULUAN Bantuan Operasional Sekolah," vol. VI, no. 3, pp. 221-230, 2020.

[11] O. Irnawati and I. Darwati, "Penerapan Model Waterfall Dalam Analisis Perancangan Sistem Informasi Inventarisasi Berbasis Web," JURTEKSI (Jurnal Teknol. dan Sist. Informasi), vol. 6, no. 2, pp. 109116, 2020.

[12] B. Wijaya and T. Sutrisno, "Penentuan Lokasi SMP Terdekat di Kabupaten Bangka Induk Berbasis Webgis," J. Sisfokom (Sistem Inf. dan Komputer), vol. 7, no. 2, p. 189, 2018. 